\title{
Light respiration in Chlorella sorokiniana
}

\author{
Anna M. J. Kliphuis • Marcel Janssen • \\ Evert J. van den End • Dirk E. Martens • \\ René H. Wijffels
}

Received: 26 April 2010 /Revised and accepted: 14 October 2010/Published online: 3 November 2010

(C) The Author(s) 2010. This article is published with open access at Springerlink.com

\begin{abstract}
Respiration and photosynthesis are two important processes in microalgal growth that occur simultaneously in the light. To know the rates of both processes, at least one of them has to be measured. To be able to measure the rate of light respiration of Chlorella sorokiniana, the measurement of oxygen uptake must be fast, preferably in the order of minutes. We measured the immediate postillumination respiratory $\mathrm{O}_{2}$ uptake rate (OUR) in situ, using fiber-optic oxygen microsensors, and a small and simple extension of the cultivation system. This method enables rapid and frequent measurements without disturbing the cultivation and growth of the microalgae. Two batch experiments were performed with C. sorokiniana in a short light-path photobioreactor, and the OUR was measured at different time points. The net oxygen production rate (net OPR) was measured online. Adding the OUR and net OPR gives the gross oxygen production rate (gross OPR), which is a measure for the oxygen evolution by photosynthesis. The gross OPR was $35-40 \%$ higher than the net OPR for both experiments. The respiration rate is known to be related to the growth rate, and it is suggested that faster algal growth leads to a higher energy (ATP) requirement, and as such, respiratory activity increases. This hypothesis is supported by our results, as the specific OUR is highest in the beginning of the batch culture when the specific growth rate is highest. In addition, the specific OUR
\end{abstract}

A. M. J. Kliphuis · M. Janssen • E. J. van den End ·

D. E. Martens $\cdot$ R. H. Wijffels

Bioprocess Engineering, Wageningen University,

Wageningen, The Netherlands

A. M. J. Kliphuis $(\bowtie)$

Bioprocess Engineering, Wageningen University, PO Box 8129, 6700 EV Wageningen, The Netherlands e-mail: Annette.Kliphuis@wur.nl decreases toward the end of the experiments until it reaches a stable value of around $0.3 \mathrm{mmol} \mathrm{O}_{2} \mathrm{~h}^{-1} \mathrm{~g}^{-1}$. This value for the specific OUR is equal to the maintenance requirement of $C$. sorokiniana as determined in an independent study of (Zijffers et al. 2010 (in press)). This suggests that respiration could fulfill the maintenance requirements of the microalgal cells.

Keywords Microalgae Chlorella sorokiniana . Respiration · Maintenance · Photosynthetic efficiency . Short light-path photobioreactor

\section{Introduction}

Respiration and photosynthesis are two important processes in microalgal growth that occur simultaneously in the light. These two processes and their relationship are extensively studied in plant science as reviewed by several authors (Badger et al. 1998; Geider and Osborne 1989; Graham 1980; Hoefnagel et al. 1998; Hunt 2003; Raghavendra et al. 1994; Turpin et al. 1988) because the balance between them determines, to a large extent, the growth and yield of most plants (Hunt 2003).

In illuminated microalgal cells, three processes in which oxygen is involved occur simultaneously. These processes are schematically shown in Fig. 1. The first process is photosynthesis in which oxygen is released, and ATP and NADPH are produced to be able to fix $\mathrm{CO}_{2}$ into glyceraldehyde 3-phosphate (GAP). This can then be converted into biomass building blocks. The second process is respiration. This process mainly takes place in the mitochondria where NADH is oxidized to generate extra energy in the form of ATP to support biomass formation and maintenance processes. In this process, 


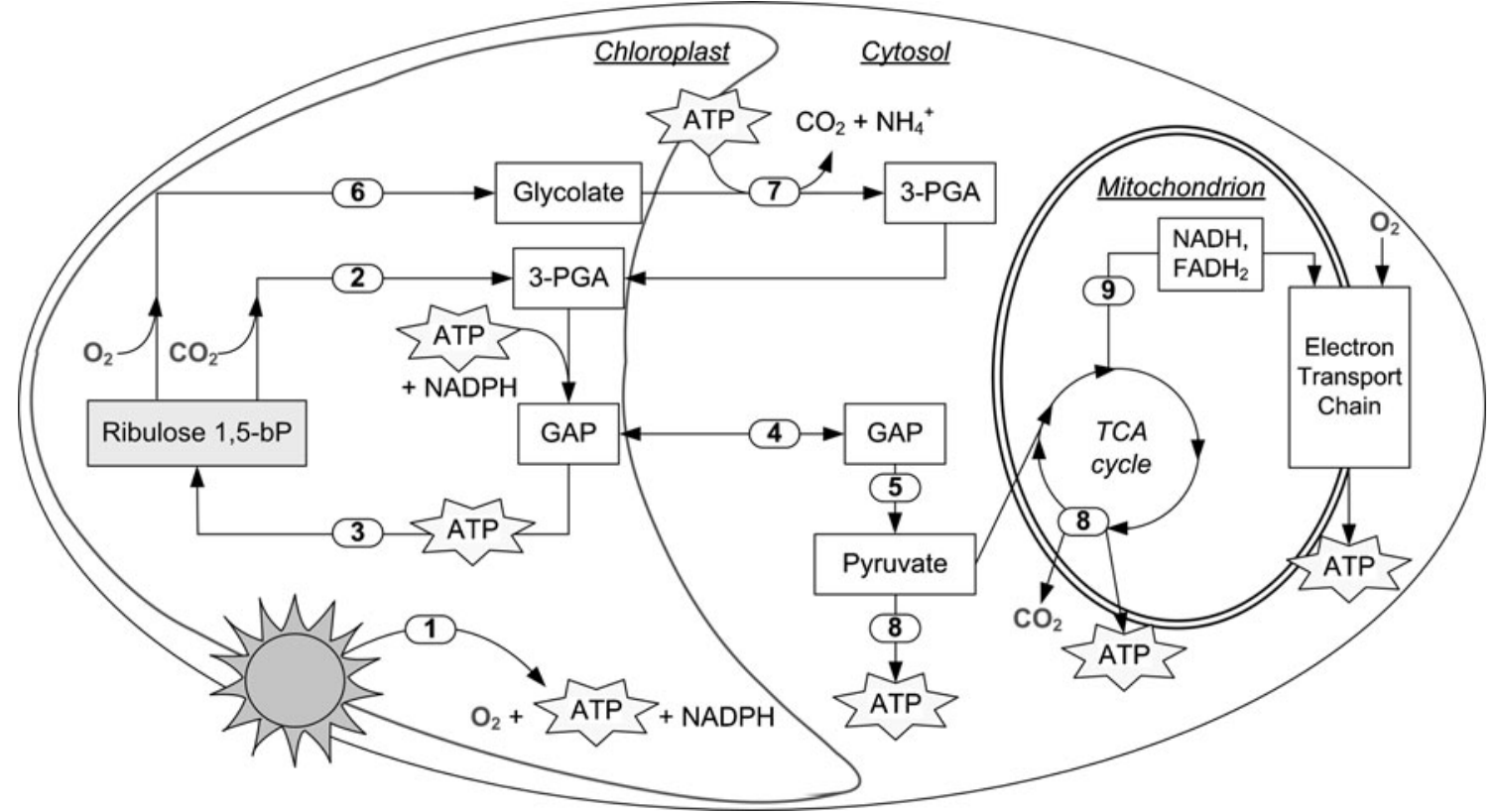

Fig. 1 Simplified overview of an algal cell in the light, showing the processes in which oxygen and energy in the form of ATP are either consumed or produced. In the chloroplast, light is fixed (1), yielding $\mathrm{O}_{2}$, NADPH, and ATP. These are needed for the fixation of carbon dioxide by Rubisco into glyceraldehyde 3-phosphate (GAP) (2). GAP can be regenerated into Ribulose 1,5-bisphosphate using ATP (3) or can be transported to the cytosol (4) to be converted into building blocks for biomass (5). The oxygenase activity of Rubisco can also fix $\mathrm{O}_{2}$, forming glycolate (6). This process is called photorespiration.

oxygen is consumed (Geider and Osborne 1989; Graham 1980; Hoefnagel et al. 1998; Turpin et al. 1988). The third process that can occur in the light is photorespiration. The oxygenase activity of Rubisco can also fix oxygen instead of carbon dioxide, forming glycolate. Glycolate is converted into glyceraldehyde 3-phosphate, so it can be re-used in biosynthesis. During this process, $\mathrm{CO}_{2}$ and ammonia are lost, which need to re-fixed. This demands substantial energy in the form of ATP and NADPH (Tural and Moroney 2005). The process of photorespiration occurs at high extracellular oxygen concentrations or at low carbon dioxide concentrations and can be neglected when this is not the case (Peltier and Thibault 1985). Photorespiration is a complex process of which the reactions are divided over several cell organelles. This is reviewed extensively by Bauwe et al. (2010), Foyer et al. (2009), Maurino and Peterhansel (2010), Ogren (1984), and Wingler et al. (2000) among others. Figure 1 shows a simplified overview of photorespiration.

To understand the energy metabolism of algal cells and with that the conversion of light energy into biomass, insight into the rates of these three processes is necessary. In this paper, we work under conditions where photorespiration can be neglected. In this situation, the net oxygen
Energy is consumed to convert glycolate into 3-phosphoglycerate (3PGA) and eventually into GAP (7), so it can enter the central carbon metabolism. During this process, $\mathrm{CO}_{2}$ and ammonium $\left(\mathrm{NH}_{4}{ }^{+}\right)$are 'lost' and need to be re-fixed elsewhere in the metabolism, costing more energy. Energy in the form of ATP is yielded through the glycolysis and TCA cycle (8). Electrons are carried via NADH and $\mathrm{FADH}_{2}$ to the electron transport chain located in the membrane of the mitochondria (9), yielding more ATP by taking up $\mathrm{O}_{2}$

exchange rate, which can be directly measured, is the sum of the oxygen production by photosynthesis and oxygen consumption through respiration in the mitochondria. To know the rates of these two processes, one of these has to be measured. In this paper, we estimate the light respiration rate by measuring the post-illumination oxygen uptake. The rate of post-illumination $\mathrm{O}_{2}$ uptake has been shown to provide a good measure for respiratory $\mathrm{O}_{2}$ uptake in the light (Grande et al. 1989; Weger et al. 1989; Xue et al. 1996). In Chlorella pyrenoidosa, respiration rates decreased from an initially high rate immediately after transfer to darkness to a much lower rate after 12-24 $\mathrm{h}$ in darkness (Geider and Osborne 1989). Bate et al. (1988) found a decline of respiration to the basal rate of steady-state dark respiration within an hour upon transfer to darkness for Dunaliella tertiolecta. This suggests that to be able to measure the rate of light respiration of $C$. sorokiniana, the measurement of post-illumination oxygen uptake must be performed immediately upon transfer to darkness. In addition, at higher biomass concentrations, the oxygen uptake rate will be high, and therefore, the oxygen concentration will decrease to zero in the order of a few minutes. Therefore, an oxygen probe with a short response time is needed. 
Widely used methods to determine respiratory $\mathrm{O}_{2}$ uptake in the light are gas analysis, mass spectrometry using oxygen isotopes and Clark-type oxygen electrodes. The advantages and disadvantages of these methods for $\mathrm{O}_{2}$ measurements are reviewed by Hunt (2003), Suresh et al. (2009), and Millan-Almaraz et al. (2009). The main drawbacks of these methods are the time scale in which measurements are possible, and the fact that for some of the methods, the algae need to be transferred from the cultivation vessel to a measurement chamber. This can cause changes in growth rate and thus in respiration rate. Fast and in situ measurements of oxygen uptake are preferred and these can be done using luminescence-based $\mathrm{O}_{2}$ sensors. These fiber-optic sensors offer advantages over electrochemical devices, such as lack of oxygen consumption, insensitivity to interfering agents, and, most important, a faster response time (López-Gejo et al. 2009). In addition, Tyystjarvi et al. (1998) found the same oxygen uptake data with fiber-optic sensors as with leaf disk $\mathrm{O}_{2}$ electrodes, indicating that measuring OUR with fiber-optic sensors is a reliable method.

This paper describes a new method to measure the rate of respiration of Chlorella sorokiniana in the light, in situ inside a short light-path (SLP) photobioreactor during cultivation, by means of a simple extension of the cultivation system. This is done by measuring the immediate postillumination $\mathrm{O}_{2}$ uptake using two types of commercially available fiber-optic oxygen microsensors. This method enables rapid and frequent measurements without disturbing the cultivation and growth of the microalgae. In the photobioreactor set-up used, the net oxygen production rate (OPR) is measured online using a gas analysis system. This net OPR represents the oxygen that is produced as a sum of all processes in the cell that either produce or consume oxygen. By measuring the oxygen uptake rate (OUR) by respiration and adding the amount of consumed oxygen to the amount of net produced oxygen, the gross OPR can be calculated giving the total rate of photosynthesis. Consequently, the method described in this paper gives insight into the different processes in which oxygen is involved in the light inside a microalgal cell, and more specifically, it gives insight into the energy requirements for biomass formation and maintenance.

\section{Materials and methods}

Chlorella sorokiniana CCAP 211/8k was obtained from the American Type Culture Collection and cultivated in 250-mL shake flasks containing $100 \mathrm{~mL}$ adapted M-8 medium (Mandalam and Palsson 1998), called M-8a (Table 1) at $\mathrm{pH}$ 6.7. The cultures were grown in a culture chamber at $25^{\circ} \mathrm{C}$, a light intensity of $20-40 \mu \mathrm{mol}$ photons $\mathrm{m}^{-2} \mathrm{~s}^{-1}$ and
Table 1 Composition of M-8a medium

\begin{tabular}{lc}
\hline Compound & Concentration $\left(\mu \mathrm{mol} \mathrm{L}{ }^{-1}\right)$ \\
\hline $\mathrm{KNO}_{3}$ & $29.67 \cdot 10^{3}$ \\
$\mathrm{KH}_{2} \mathrm{PO}_{4}$ & $5.44 \cdot 10^{3}$ \\
$\mathrm{Na}_{2} \mathrm{HPO}_{4} \cdot 2 \mathrm{H}_{2} \mathrm{O}$ & $1.46 \cdot 10^{3}$ \\
$\mathrm{MgSO}_{4} \cdot 7 \mathrm{H}_{2} \mathrm{O}$ & $1.62 \cdot 10^{3}$ \\
$\mathrm{CaCl}_{2} \cdot 2 \mathrm{H}_{2} \mathrm{O}$ & 88.43 \\
$\mathrm{EDTA} \mathrm{ferric} \mathrm{sodium} \mathrm{salt}$ & 315.86 \\
$\mathrm{Na}_{2} \mathrm{EDTA}_{2} 2 \mathrm{H}_{2} \mathrm{O}$ & 100.00 \\
$\mathrm{H}_{3} \mathrm{BO}_{3}$ & 1.00 \\
$\mathrm{MnCl}_{2} \cdot 4 \mathrm{H}_{2} \mathrm{O}$ & 65.59 \\
$\mathrm{ZnSO}_{4} \cdot 7 \mathrm{H}_{2} \mathrm{O}$ & 11.13 \\
$\mathrm{CuSO}_{4} \cdot 5 \mathrm{H}_{2} \mathrm{O}$ & 7.33 \\
\hline
\end{tabular}

a 16/8 h day/night cycle. To reach inoculation cell density, the cultures were placed in a shake incubator for 2 days at a continuous light intensity of $280 \mu \mathrm{mol}$ photons $\mathrm{m}^{-2} \mathrm{~s}^{-1}$ and a head space enriched with $5 \% \mathrm{CO}_{2}$.

For the experiments in the photobioreactor, three times concentrated M-8a medium was used to be able to reach high cell densities. The concentration $\mathrm{KNO}_{3}$ was decreased to $5 \mathrm{mmol} \mathrm{L}^{-1}$, since $\mathrm{HNO}_{3}$ was added on-demand via the $\mathrm{pH}$ control.

Reactor set-up C. sorokiniana was grown in batch mode in a SLP photobioreactor, depicted schematically in Fig. 2. This photobioreactor design is described in more detail in Kliphuis et al. (2010). The photobioreactor had a working volume of $3.4 \mathrm{~L}$, an annular gap width of $12 \mathrm{~mm}$ and an illuminated area $\left(A_{\mathrm{pbr}}\right)$ of $0.24 \mathrm{~m}^{2}$. The radius of the rotating inner cylinder $\left(r_{\mathrm{i}}\right)$ was $0.076 \mathrm{~m}$, and the radius of the stationary outer cylinder $\left(r_{\mathrm{o}}\right)$ was $0.088 \mathrm{~m}$. Therefore, the radius ratio $\left(\eta=r_{\mathrm{i}} / r_{\mathrm{o}}\right)$ of the photobioreactor was $0.076 \mathrm{~m} / 0.088 \mathrm{~m}=0.86$.

The inner cylinder was rotating at a speed of $70 \mathrm{rpm}$ during the batch cultivations. To enable vertical backmixing, four down comers were drilled into the inner cylinder. Without down comers in the inner cylinder, no vertical back mixing occurred and the algae accumulated in the top part of the photobioreactor. By adding the down comers, the algae were mixed over the whole annular gap.

Light was provided continuously by 60 tungsten-halogen lamps (Philips Masterline ES 45W) surrounding the reactor. The photon flux density (PFD) was measured with a LICOR 190-SA $2 \pi$ sensor (PAR range, $400-700 \mathrm{~nm}$ ) at 80 fixed points inside the reactor before each experiment. The measured light intensities at all 80 points were averaged into a PFD for that particular experiment. An average light intensity of $1,500 \mu \mathrm{mol}$ photons $\mathrm{m}^{-2} \mathrm{~s}^{-1}$ could be reached with this set-up. The light intensity applied in these experiments $\left(\sim 1,500 \mu \mathrm{mol}\right.$ photons $\left.\mathrm{m}^{-2} \mathrm{~s}^{-1}\right)$ is comparable 
Fig. 2 Schematic overview (not on scale) of the SLP photobioreactor. $A$ annular gap, $C$ condenser, $D$ internal down comer, $D O$ dissolved oxygen sensor, $G A$ gas analyzer, $I$ inner cylinder, $L$ spherical light sensor, $M$ motor, $M F C$ mass flow controllers for both $\mathrm{N}_{2}$ and $\mathrm{CO}_{2}$, $\mathrm{pH} \mathrm{pH}$ control connected to acid pump, $S$ sparger, $T$ temperature control connected to cryostat and cooling jacket (not shown)

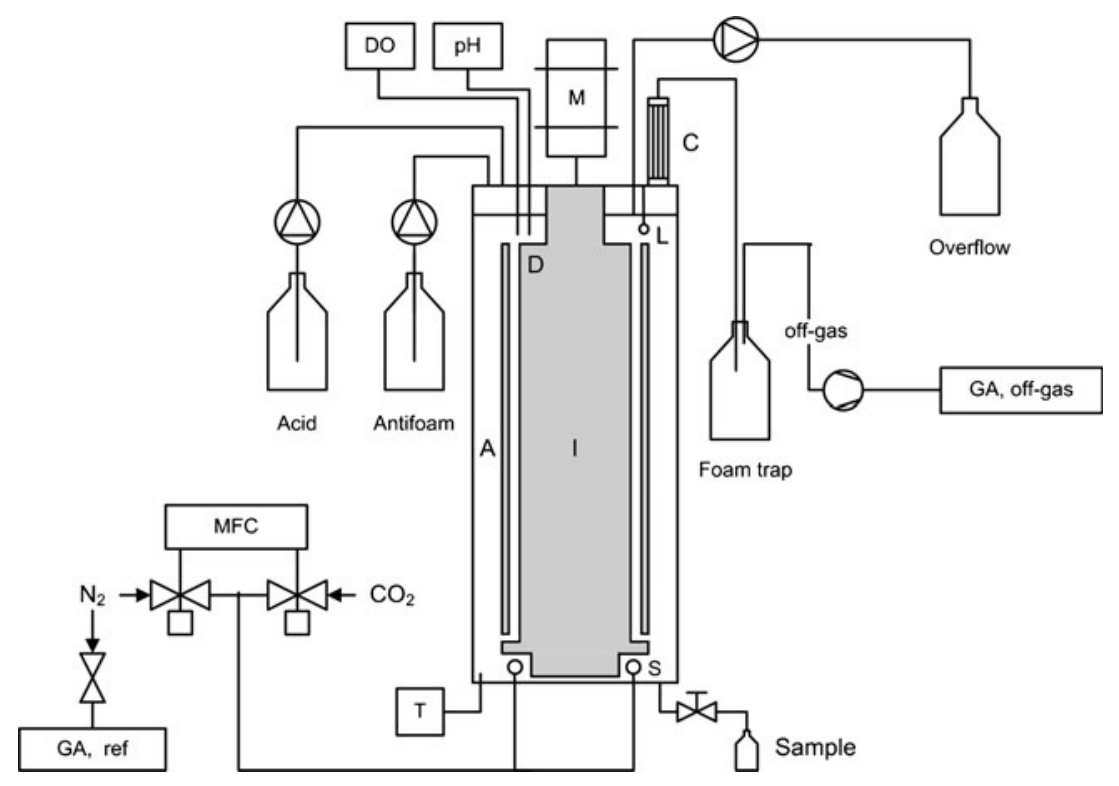

to horizontal solar irradiance in the Netherlands at the peak of summer.

During the experiments, the transmitted irradiance through the culture was measured by a spherical light sensor (US-SQS Spherical Micro Quantum Sensor, Heinz Walz Gmbh, Germany) placed inside the culture broth at the depth of the annular gap, $12 \mathrm{~mm}$ from the internal reactor wall, as illustrated in Fig. 2.

Using mass flow controllers (Brooks, Smart TMF 5850S), carbon dioxide was supplied by sparging nitrogen $\left(1.55 \mathrm{~L} \mathrm{~min}^{-1}\right.$ ) enriched with $2 \%$ carbon dioxide through a silicone ringsparger at the bottom of the reactor. This gas flow also served to remove excess oxygen from the culture broth. The $\mathrm{pH}$ was controlled at $\mathrm{pH} 6.7 \pm 0.1$ by pumping nitric acid $(1.7 \mathrm{M})$, serving also as nitrogen source. The acid bottle, antifoam bottle, and overflow bottle were placed on balances and weighed online. The reactor was kept at $37^{\circ} \mathrm{C}$, the optimal temperature for C. sorokiniana (Sorokin and Myers 1953), by a water jacket connected to a temperature-controlled water bath. To prevent water from evaporating into the off-gas, the reactor was equipped with a condenser connected to a cryostat set at $2^{\circ} \mathrm{C}$. Biomass samples were taken from the bottom of the reactor and weighed offline.

Online gas analysis and calculations The off-gas was analyzed by leading it over a gas analyzer (Servomex, 4100) fitted with two different gas sensor modules, a paramagnetic purity transducer to measure oxygen and an infrared 1500 transducer to measure $\mathrm{CO}_{2}$.

Before each experiment, a dry and a wet baseline were measured to correct the experimental gas data for moisture content according to Eq. 1. The dry baseline was measured by leading $1.55 \mathrm{~L} \mathrm{~min}^{-1} \mathrm{~N}_{2}$ enriched with $2 \% \mathrm{CO}_{2}$ over the gas analyzers. For the wet baseline, the $\mathrm{N}_{2}$ enriched with $\mathrm{CO}_{2}$ was first sparged through the reactor, containing medium at the same temperature and $\mathrm{pH}$ as during the batch experiment, and through the condenser before being analyzed.

$n_{\text {gas }, \text { out }}=n_{\text {gas, in }} \frac{x_{\mathrm{CO}_{2}, \mathrm{db}}}{x_{\mathrm{CO}_{2}, \mathrm{wb}}}$

The total molar gas flow going in $\left(n_{\text {gas,in }}, \mathrm{mmol} \mathrm{h}^{-1}\right)$ is corrected for the molar fraction of carbon dioxide in both the dry $\left(x_{\mathrm{CO}_{2}, \mathrm{db}}\right)$ and wet baseline $\left(x_{\mathrm{CO}_{2}, \mathrm{wb}}\right)$. With this corrected molar gas flow $n_{\text {gas,out }}\left(\mathrm{mmol} \mathrm{h}^{-1}\right)$ and the molar fraction of oxygen $\left(x_{\mathrm{O}_{2}, \exp }\right)$ and carbon dioxide $\left(x_{\mathrm{CO}_{2}, \exp }\right)$ measured during the experiments, the oxygen production rate $\left(\mathrm{OPR}, \mathrm{mmol} \mathrm{h} \mathrm{h}^{-1}\right.$ ) and $\mathrm{CO}_{2}$ uptake rate (CUR, $\mathrm{mmol} \mathrm{h}$ ) are calculated according to Eqs. 2 and 3.

$\mathrm{OPR}=\frac{n_{\text {gas,out }}\left(x_{\mathrm{O}_{2}, \exp }-x_{\mathrm{O}_{2}, \mathrm{wb}}\right)}{100}$

$\mathrm{CUR}=\frac{n_{\text {gas,out }}\left(x_{\mathrm{CO}_{2}, \text { exp }}-x_{\mathrm{CO}_{2}, \mathrm{wb}}\right)}{100}$

The ratio between the OPR and CUR is the photosynthetic quotient PQ ( $\mathrm{mol} \mathrm{O} \mathrm{O}_{2}$ evolved/mol $\mathrm{CO}_{2}$ consumed). The PQ can be calculated according to Eq. 4:

$\mathrm{PQ}=\frac{\mathrm{OPR}}{\mathrm{CUR}}$

The observed biomass yield on light energy ( $Y_{\mathrm{x}, \mathrm{E}(\mathrm{obs})}$, $\mathrm{g} \mathrm{mol}^{-1}$ ) is defined as gram dry biomass formed per mol incident photons on the photobioreactor surface according to Eq. 5. The photon flux $\left(\mathrm{PF}_{\mathrm{in}}, \mathrm{mmol}\right.$ photons $\left.\mathrm{h}^{-1}\right)$ is calculated using the measured average photon flux density 
$\left(\mathrm{PFD}_{\mathrm{in}}, \mu \mathrm{mol}\right.$ photons $\mathrm{m}^{-2} \mathrm{~s}^{-1}$ ) and the illuminated photobioreactor area $A_{\mathrm{pbr}}\left(\mathrm{m}^{2}\right)$ described earlier. We assumed that all consumed carbon is converted into biomass. The dry biomass $\mathrm{C}-$ molar mass $\left(M_{\text {biomass }}, \mathrm{g} \mathrm{mol}^{-1}\right)$ was determined as described in the next paragraph.

$Y_{x, E(\mathrm{obs})}=\frac{\mathrm{CUR} \times M_{\text {biomass }}}{\mathrm{PF}_{\text {in }}}$

The theoretical maximal biomass yield $\left(Y_{x E \max }\right)$ for growth on nitrate is estimated to be $1.57 \mathrm{~g}$ dry weight per mol of photons (quanta) (calculation in Kliphuis et al. 2010).

Respiration measurements Oxygen uptake through respiration (OUR) was measured using two different fiber-optic oxygen microsensors as shown in Table 2 . In experiment I, the OceanOptics (OO) microsensor was used, and in experiment II, the PreSens (PS) microsensor was used.

The measurement principle of both oxygen microsensors is based on the effect of dynamic fluorescence quenching by molecular oxygen. Light pulses by a light-emitting diode (LED) $(475 \mathrm{~nm})$ are sent to the tip of the microsensor coated by a $\mathrm{Ru}(\mathrm{II})$ complex, which is excited by the light. The excited complex fluoresces at $600 \mathrm{~nm}$. If the excited complex encounters an oxygen molecule, the excess energy is transferred to the oxygen molecule, quenching the fluorescence signal. Therefore, when more oxygen is present, more of the fluorescence will be quenched, resulting in lower fluorescence. The fluorescence light is collected by the probe, transported through the optical fiber to the detector and translated into an oxygen concentration. The OceanOptics microsensor translates the fluorescence intensity (or phase shift) to an oxygen concentration. The PreSens microsensor translates the fluorescence decay time to an oxygen concentration. This decay time is the phase angle between the exciting and the emitted signal and is shifted as a function of the oxygen concentration. The PreSens microsensor was equipped with an optically isolated sensor tip to exclude intrinsic chlorophyll florescence from the microalgae cells.

To be able to measure the oxygen uptake rate of $C$. sorokiniana inside the photobioreactor, the fiber-optic microsensors needed to be calibrated in M- 8 a medium at $37^{\circ} \mathrm{C}$. The OceanOptics microsensor was calibrated using a second order polynomial algorithm (non-linear SternVolmer relationship) for which three standards with known $\mathrm{O}_{2}$ concentration were needed. $\mathrm{M}-8 \mathrm{a}$ medium at $37^{\circ} \mathrm{C}$ saturated with $\mathrm{N}_{2}$ was used as $0 \%$ air saturation, with pressurized air as $100 \%$ air saturation and with pure $\mathrm{O}_{2}$ as $476.2 \%$ air saturation. The PreSens microsensor was calibrated using the linear Stern-Volmer algorithm for which two standards with known $\mathrm{O}_{2}$ concentration were needed. Therefore, $\mathrm{M}-8 \mathrm{a}$ medium at $37^{\circ} \mathrm{C}$ saturated with $\mathrm{N}_{2}$ as $0 \%$ air saturation and with pressurized air as $100 \%$ air saturation were used. The output of the fiber-optic microsensors was $\mathrm{O}_{2}$ concentration in percentage of air saturation. The concentration dissolved $\mathrm{O}_{2}$ in $\mathrm{mmol} \mathrm{L}^{-1} \mathrm{M}-8 \mathrm{a}$ medium could be calculated from the percentage of air saturation by correcting for the temperature and salinity of the M-8a medium according to Quicker et al. (1981).

A dark tube with a volume of $8 \mathrm{~mL}$, closed with a septum was placed in the top of the photobioreactor, hanging in the culture broth as shown schematically in Fig. 3. The fiber-optic oxygen microsensor was inserted into the dark tube through the septum with help of a needle. Algae were sucked into the dark tube through a small hole (Ø $1 \mathrm{~mm})$ in the bottom of the tube using a needle and a syringe. As soon as the algae are in the dark, they will immediately stop photosynthesizing, and oxygen uptake through respiration can be measured by logging the decrease in oxygen concentration in time. The microsensors were connected to the corresponding detectors, which were in turn connected to a PC logging the data using the corresponding software supplied with the microsensors. Before and after each measurement, the tube was flushed with air.

Oxygen uptake rate calculation The slope of the decrease in oxygen concentration ( $\mathrm{mmol} \mathrm{kg} \mathrm{kg}^{-1} \mathrm{~h}^{-1}$ ) is multiplied by the reactor volume $\left(\mathrm{V}_{\mathrm{pbr}}, \mathrm{kg}\right)$ to give the OUR in $\mathrm{mmol} \mathrm{h}^{-1}$, according to Eq. 6 :

$\operatorname{OUR}(t)=$ slope $\times V_{\text {pbr }}$

In previous experiments with C. sorokiniana, we observed the formation of a biofilm when the batch experiment was kept running for longer than $60 \mathrm{~h}$ and biomass densities increased to more than $10 \mathrm{~g} \mathrm{~L}^{-1}$. The cells forming this biofilm were not detectable with dry weight measurements but were most probably still alive and actively contributing to $\mathrm{O}_{2}$ production and consumption in the photobioreactor. The total accumulation of biomass, so the cells in suspension and the live cells in biofilm, at each time point during the cultivation $\left(C_{\mathrm{x}, \text { tot }}(t), \mathrm{g}\right)$ can be

Table 2 Two types of fiber-optic oxygen microsensors used in this study

\begin{tabular}{llll}
\hline Type of microsensor & Measuring method & Response time & Experiment \\
\hline AL-300 FOXY (OceanOptics) & Fluorescence intensity & $<1$ s (no optical isolation) & I \\
NTH-PSt1-L2.5-TS-NS40/0.4-YOP (PreSens) & Fluorescence decay time & $<1$ s (optical isolation) & II \\
\hline
\end{tabular}




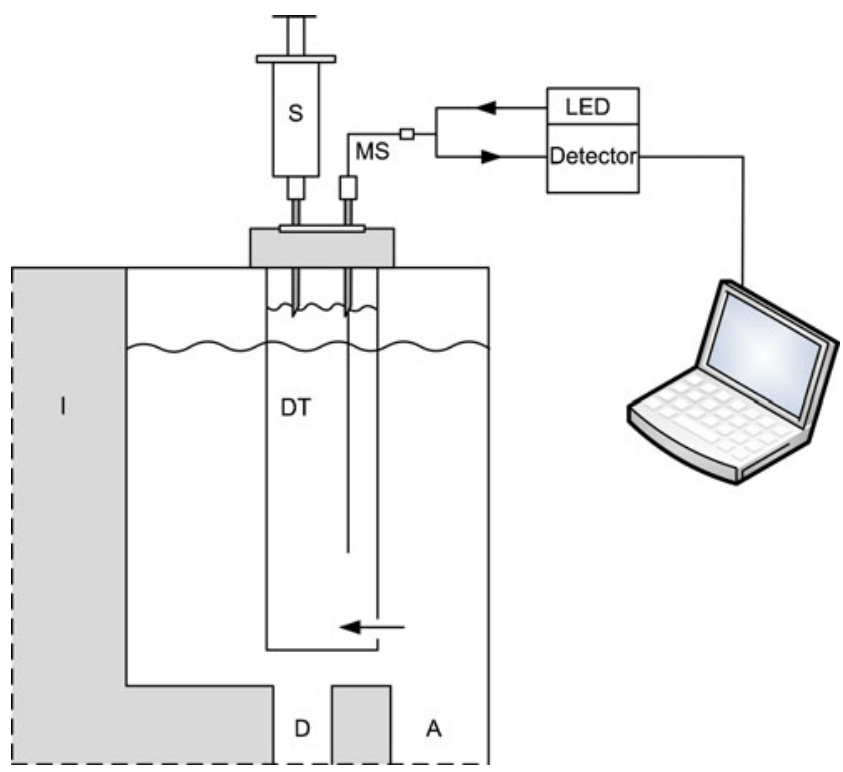

Fig. 3 Schematic overview of the OUR measurement setup (not to scale).The algae are sucked into the dark tube using a syringe. The OUR of the algae is measured by a fiber-optic microsensor connected to a light source (LED) and a detector to detect the fluorescence quenching by oxygen at the sensor tip. The detector in turn is connected to a PC with the designated software to log the oxygen uptake in time. $A$ annular gap, $D$ internal down comer, $D T$ dark tube, $I$ inner cylinder, $M S$ microsensor, $S$ syringe

calculated from the CUR $(\operatorname{CUR}(t)$, mol). For this, we assume that every mol of $\mathrm{CO}_{2}$, which is taken up is converted into $1 \mathrm{C}$-mol of dry biomass with a known molecular weight $\left(\mathrm{M}_{\text {biomass }}, \mathrm{g} \mathrm{mol}^{-1}\right)$, according to Eq. 7 .

$C_{x, \text { tot }}(t)=C_{x}(0)+\int_{0}^{t} \operatorname{CUR}(t) M_{\text {biomass }} \mathrm{d} t$

To calculate the cumulative CUR, the amount of inoculum had to be added to the CUR at $t=0\left(C_{x}(0), \mathrm{g}\right)$. The elemental composition and molecular weight of $\mathrm{C}$. sorokiniana biomass was $\mathrm{CH}_{1.71 \pm 0.01} \mathrm{O}_{0.40 \pm 0.02} \mathrm{~N}_{0.15 \pm 0.004}$ with a $M_{\text {biomass }}$ of $23.682 \mathrm{~g} \mathrm{~mol}^{-1}$ (including ash), as determined by Kliphuis et al. (2010).

This total biomass can be compared with the measured dry weight of the cells in suspension to assess whether there was biofilm formation during the experiment. If biofilm formation takes place in the photobioreactor, it is not possible to determine if that is also the case inside the dark measuring tube. Therefore, we can calculate two values for the OUR. If we assume that inside the dark tube, the same biofilm is built-up as in the rest of the photobioreactor and that this biofilm actively contributes to the OUR, the measured OUR in $\mathrm{mmol} \mathrm{h}^{-1}$ represents the OUR for the whole reactor. If, however, there is no biofilm build-up inside the dark tube or the biofilm would be inactive due to the darkness in the tube, the measured OUR is only caused by the cells in suspension, which are sucked into the tube. This measured OUR in mmol h${ }^{-1}$ then only represents the cells in suspension. To be able to calculate the OUR for the whole reactor, we then need to correct for the cells that are present in the form of biofilm in the photobioreactor, hence OUR $_{\text {corr }}$

With the measured dry weight, we first calculate the specific OUR per biomass $\left(\mathrm{OUR}_{\text {spec }}(t), \mathrm{mmol} \mathrm{h}^{-1} \mathrm{~g}^{-1}\right)$ by dividing the OUR at time $t\left(\mathrm{mmol} \mathrm{h}^{-1}\right)$ with the measured dry weight at that time $\left(C_{x}(t), \mathrm{g}\right)$ according to Eq. 8 :

$\operatorname{OUR}_{\text {spec }}(t)=\frac{\operatorname{OUR}(t)}{C_{x}(t)}$

Then, by multiplying with the total biomass present in the reactor $\left(C_{x, \text { tot }}(t), \mathrm{g}\right)$ calculated from the CUR (Eq. 7), the $\operatorname{OUR}_{\text {corr }}\left(\mathrm{mmol} \mathrm{h}^{-1}\right)$ can be calculated with Eq. 9:

$\operatorname{OUR}_{\text {corr }}(t)=\operatorname{OUR}_{\text {spec }}(t) \times \mathrm{C}_{\mathrm{x}, \text { tot }}(t)$

The resulting OUR, whether corrected or not, can be added up to the Net OPR at time $t\left(\mathrm{OPR}, \mathrm{mmol} \mathrm{h}^{-1}\right)$ as measured with gas analysis at that time point, according to Eq. 10 . This gives the gross OPR ( $\left.\mathrm{OPR}_{\text {gross }}\right)$ at time $t\left(\mathrm{mmol} \mathrm{h}^{-1}\right)$, which shows the total oxygen evolution at that time point.

$\operatorname{OPR}_{\text {gross }}(t)=\operatorname{OPR}(t)+\operatorname{OUR}_{\text {(corr) }}(t)$

\section{Biomass determinations}

Cell number and cell size were determined with a Beckman Coulter Multisizer 3 (Beckman Coulter Inc., USA, $50 \mu \mathrm{m}$ orifice). The samples were diluted with filtered $(0.2 \mu \mathrm{m})$ Coulter ${ }^{\circledR}$ Isoton ${ }^{\circledR}$ II dilution buffer to a cell concentration between $1 \times 10^{5}$ and $3 \times 10^{5}$ cells $\mathrm{mL}^{-1}$. The cell number and cell size were used to calculate the total biovolume.

For dry weight determination, Whatman GF/F glass microfiber filters (Ø $55 \mathrm{~mm}$, pore size $0.7 \mu \mathrm{m})$ were dried at $95^{\circ} \mathrm{C}$ overnight and placed in a desiccator to cool to room temperature. The dry filters were weighed and prewet with de-mineralized water. Two grams of sample were diluted with de-mineralized water and filtrated under mild vacuum ( 0.67 bar absolute). The filter was rinsed twice with de-mineralized water to remove adhering inorganic salts. The wet filters containing the samples were dried again at $95^{\circ} \mathrm{C}$ overnight, allowed to cool to room temperature in a desiccator, and weighed. The difference in weight between the dry filters containing the samples and the empty weight was the dry weight of the samples.

\section{Results}

Two batch experiments were performed with $C$. sorokiniana in a SLP photobioreactor. The mixing in the SLP photo- 
bioreactor was accomplished by rotating the inner tube at $70 \mathrm{rpm}$. The results of these batch experiments can be seen in Fig. 4. Figure 4a shows the net oxygen production rate (OPR) and carbon dioxide uptake rate (CUR) obtained by duplicate batch cultivations (I and II). After inoculating with a very low biomass density, the algae were grown at a light intensity of $200 \mu \mathrm{mol}$ photons $\mathrm{m}^{-2} \mathrm{~s}^{-1}$. When the biomass concentration increased to $0.1 \mathrm{~g} \mathrm{~L}^{-1}$ dry weight, the light was increased to $600 \mu \mathrm{mol}$ photons $\mathrm{m}^{-2} \mathrm{~s}^{-1}$. When the biomass concentration reached $1.2 \mathrm{~g} \mathrm{~L}^{-1}$ dry weight, the light was increased to $1,500 \mu \mathrm{mol}$ photons $\mathrm{m}^{-2} \mathrm{~s}^{-1}$, which is the light intensity of interest. After this increase in light supply to $1,500 \mu \mathrm{mol}$ photons $\mathrm{m}^{-2} \mathrm{~s}^{-1}$ at $23 \mathrm{~h}$, the OPR and CUR increased dramatically and continued to increase until an optimum was reached at $27 \mathrm{~h}$. After reaching this optimum at a biomass density of $2.3 \mathrm{~g} \mathrm{~L}^{-1}$ dry weight, the OPR and CUR decreased again until the batch was ended.
The PQ values for the duplicate experiments are also shown in Fig. 4a. When the light was increased to $1,500 \mu \mathrm{mol}$ photons $\mathrm{m}^{-2} \mathrm{~s}^{-1}$, the PQ fluctuated and finally stabilized at a value of 1.34 for both duplicate experiments. The PQ value shows that if the composition of the produced biomass changes (Eriksen et al. 2007), different substrates are used or other products are formed, thus serving as a control parameter for photoautotrophic growth. In this case, the PQ for both experiments shows the same trend and the same values, indicating that the growth of both cultures was comparable. The fluctuation of the PQ observed after the light increase to $1,500 \mu \mathrm{mol}$ photons $\mathrm{m}^{-2} \mathrm{~s}^{-1}$ is probably related to changes in biomass composition as for example a change in the amount of stored carbohydrates.

During the experiments the light penetrating the culture was measured by a spherical PAR sensor hanging inside the culture at the depth of the annular gap as shown in Fig. 4b.
Fig. 4 Detailed overview of duplicate batch experiments I and II at a mixing rate of $70 \mathrm{rpm}$. a Oxygen production rates (OPR), carbon dioxide uptake rates (CUR) (in $\mathrm{mmol} \mathrm{h}^{-1}$ ) and photosynthetic quotient (PQ) for both experiments. All data are normalized for the time point of light increase to $1,500 \mu \mathrm{mol}$ photons $\mathrm{m}^{-2} \mathrm{~s}^{-1}$, which is indicated with a dotted line. b Total biomass present in the reactor (in $\mathrm{g}$ ) as calculated from the CUR as well as the measured dry weight present in the reactor (in $g$ ) for duplicate batch experiments I and II. Also plotted is the transmitted irradiance through the culture during the batch experiment. The two peaks indicate the stepwise light increase, the first time to $600 \mu \mathrm{mol}$ photons $\mathrm{m}^{-2} \mathrm{~s}^{-1}$ when the biomass is still relatively low and the second time to $1,500 \mu \mathrm{mol}$ photons $\mathrm{m}^{-2} \mathrm{~s}^{-1}$. This second light increase is indicated with a dotted line
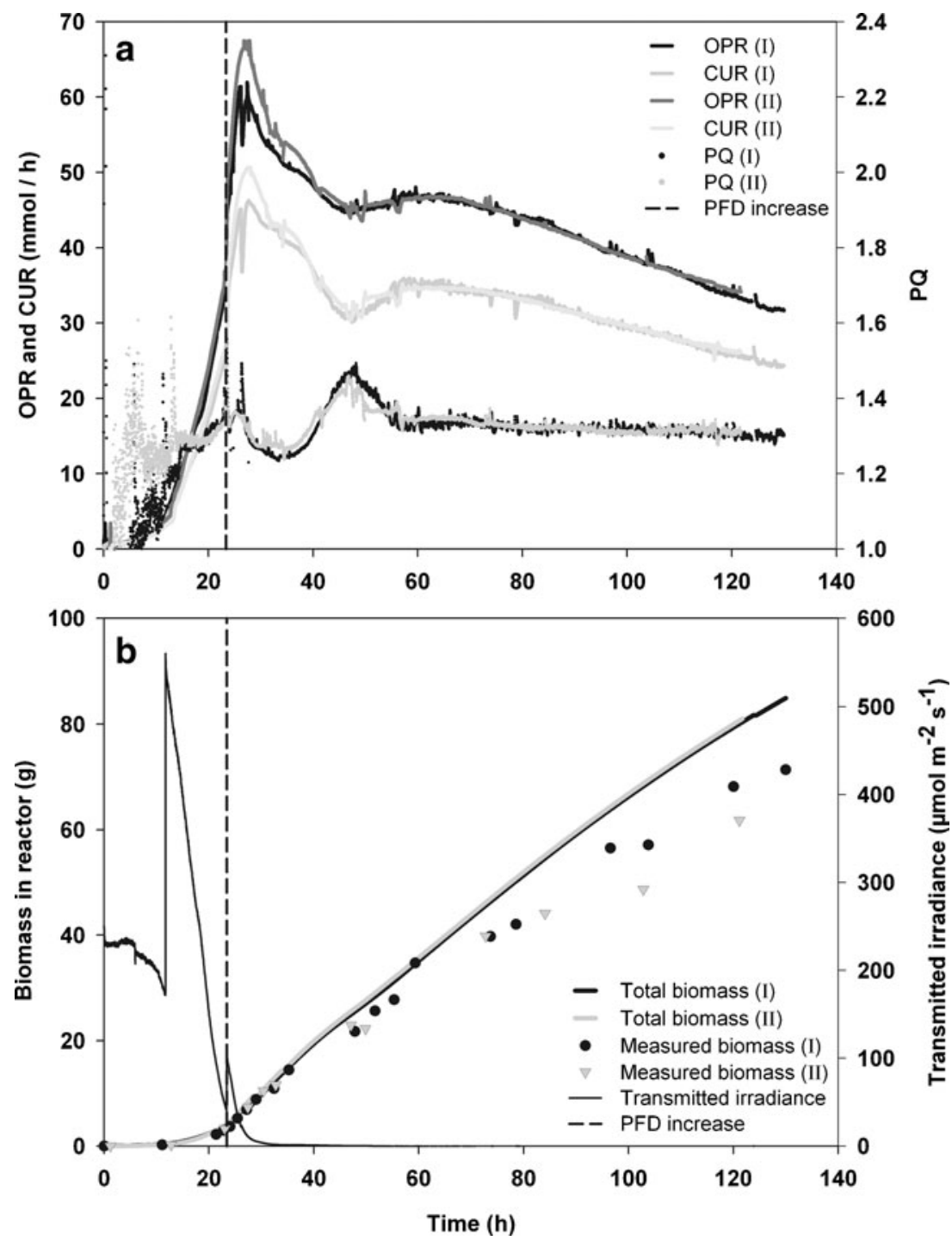
The stepwise light increase can be clearly seen as well as the fast decrease of light penetrating the culture when the biomass increased. At the optimum OPR and CUR, all the light was absorbed in the annular gap.

The biomass dry weight present in the reactor is plotted in Fig. 4b for both experiments. Both the measured biomass, representing the biomass in suspension as determined by dry weight measurements, and the calculated total biomass, representing all the biomass present in the reactor calculated with Eq. 7, are given. In the beginning of the batch experiments, the measured and the calculated total biomass were equal, but during the experiment, as the biomass density increased above $10 \mathrm{~g} \mathrm{~L}^{-1}$, these values started to deviate. This deviation was due to the formation of a biofilm. During the experiments, especially experiment II, a thin biofilm formed on the reactor wall, which contributed to the OPR and CUR but could not be measured by taking samples and measuring dry weight because these only represented the cells present in suspension.

\section{Respiration measurements}

During the batch experiments, respiration was quantified by measuring the OUR of the microalgae inside the dark tube. Figure 5 shows such a duplicate measurement. When the algae were sucked into the dark tube, the starting $\mathrm{O}_{2}$ concentration was the same as in the photobioreactor at that time point. Then, the $\mathrm{O}_{2}$ concentration started to decrease due to $\mathrm{O}_{2}$ uptake by respiration. All oxygen was consumed after about $4 \mathrm{~min}$, and after a while, the tube was flushed, and new algae were sucked into the dark for a duplicate

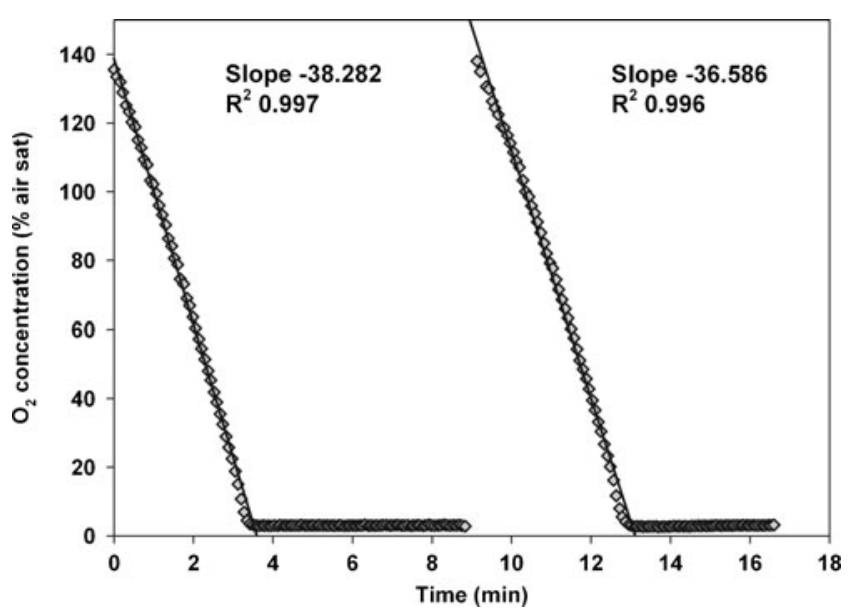

Fig. 5 Duplicate OUR measurement. Upon transfer to the dark the microalgae consumed the oxygen present in the liquid. The starting oxygen concentration was equal to the DO in the photobioreactor. When all oxygen was consumed, the tube was flushed, and the process was repeated for a duplicate measurement at that time point. At the same time, one biomass sample was taken. The oxygen concentration was measured in percentage of air saturation. The slope represents the OUR and was converted to $\mathrm{mmol} \mathrm{h}^{-1}$ using Eq. 6 measurement. The $\mathrm{O}_{2}$ concentration in $\%$ air saturation was converted to $\mathrm{mmol} \mathrm{L}^{-1}$ as described before, and the slope thus gave the OUR $(t)$ in $\mathrm{mmol} \mathrm{h}^{-1}$ (Eq. 6). This measurement was performed at different time points during the batch (either in duplicate or triplicate), and a biomass sample was taken from the bottom of the photobioreactor simultaneously. Figure $4 \mathrm{~b}$ shows a deviation between the measured and calculated biomass content of the bioreactor at higher biomass concentrations, and we observed the formation of a thin biofilm. This biofilm formation starts at high biomass concentrations of over $10 \mathrm{~g} \mathrm{~L}^{-1}$ and becomes more pronounced at even higher concentrations of around $20 \mathrm{~g} \mathrm{~L}^{-1}$ dry weight. These biomass concentrations are very high for microalgal cultivations. The algae are probably very light limited at that point and likely react to this by forming a thin biofilm. To be able to also judge respiration and gross OPR at these high biomass concentrations, the OUR was also corrected according to Eq. 9. This correction was performed assuming no biofilm build-up in the dark tube and only in the photobioreactor. This correction also reflects the situation if a possible biofilm inside the dark tube would be inactive due to the darkness in the tube. The uncorrected OUR gives the values for the assumption that there was a biofilm in the dark tube, and the build-up was equal to that in the whole bioreactor. Both values will be given in all figures to show the two most extreme scenarios, and the margin of error that can be due to biofilm formation at (very) high biomass densities.

Figure 6a shows the OUR data for experiment I, and Fig. $6 \mathrm{~b}$ shows the OUR data for experiment II. Both graphs show the net OPR as measured online and the OUR measured with the oxygen microsensors, indicated with triangles. The values for both OUR and OUR $\mathrm{R}_{\text {corr }}$ are equal in the beginning of the experiment and start to deviate in time, due to the biofilm increasing in size. Both OUR and OUR $_{\text {corr }}$ follow the same pattern for both experiments.

Figure 6 also shows the gross OPR for both experiments, indicated with circles. The net OPR is measured online based on the gas analysis and represents the oxygen that is produced as a sum of all processes in the cell that either produce or consume oxygen. In photosynthesis, $\mathrm{O}_{2}$ is produced, but in mitochondrial respiration $\mathrm{O}_{2}$ is consumed again. This is not reflected in the net OPR, but by measuring the OUR and adding the amount of consumed $\mathrm{O}_{2}$ to the amount of net produced oxygen, the gross OPR can be calculated. The OUR and gross OPR increase with increasing net OPR and stabilize after the optimum OPR is reached. The gross OPR is $30-45 \%$ higher than the net OPR.

From the OUR and the simultaneous biomass measurements, the specific OUR could be calculated according to Eq. 8. To obtain the corrected specific OUR, the measured OUR was divided by the total biomass $C_{x \text {,tot }}$ calculated according to Eq. 7. These data are shown in Fig. 7 for both 


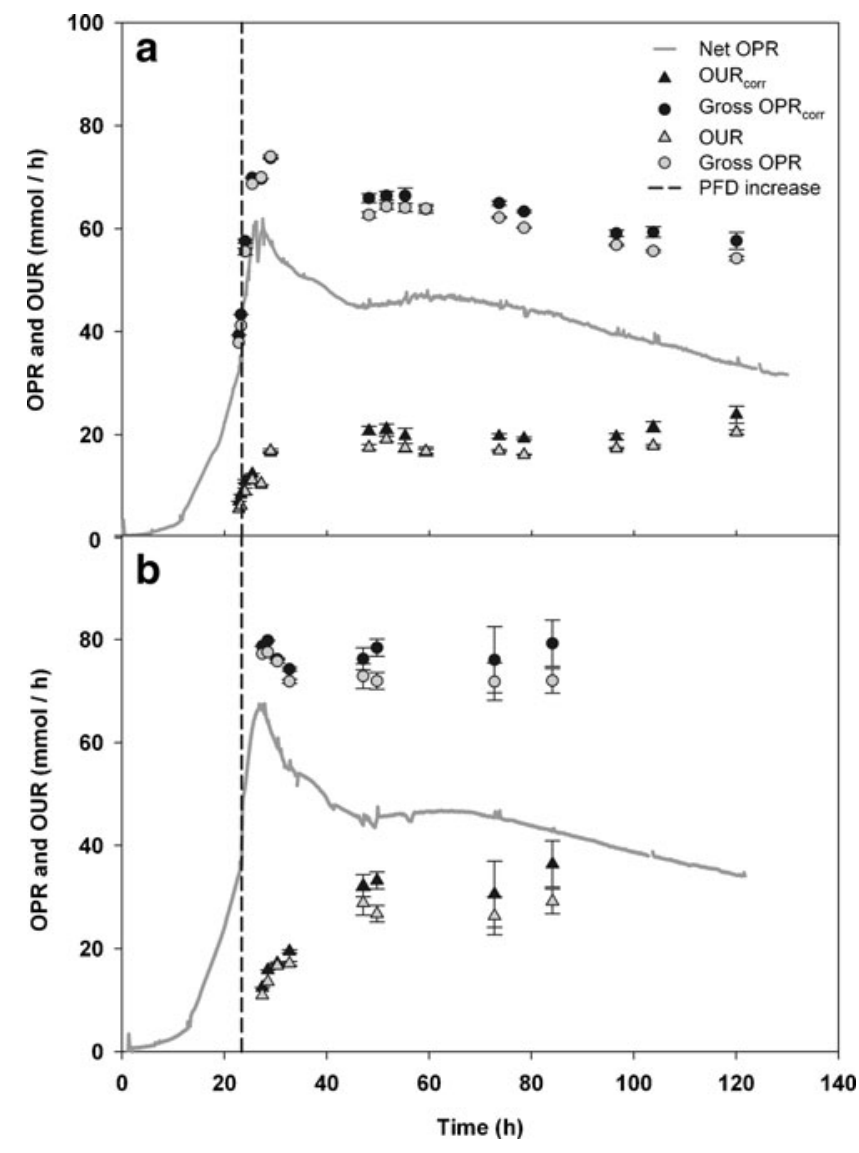

Fig. 6 Oxygen uptake rates and gross oxygen production rates (OPR) for duplicate batch experiments I (a) and II (b) at $70 \mathrm{rpm}$. The net oxygen production rate (net OPR) was measured online during the batch cultivations. The OUR was measured with the oxygen microsensors at different time points as indicated with triangles. The error bars represent the standard deviation of duplicate or triplicate OUR measurements at that time point. Adding up the OUR and the net OPR at these time points gives the gross OPR, indicated with circles. The closed symbols give the corrected values for OUR (OUR $\mathrm{Corr}_{\text {r }}$ ), assuming no biofilm build-up in the dark tube and only in the photobioreactor. The open symbols give the values for OUR for the assumption that there was a biofilm in the dark tube, and the build-up was equal to that in the whole bioreactor. The light increase to $1,500 \mu \mathrm{mol}$ photons $\mathrm{m}^{-2} \mathrm{~s}^{-1}$ is indicated by a dotted line

experiments I and II. The online measured OPR for both experiments is shown, and the dotted line represents the light increase to $1,500 \mu \mathrm{mol}$ photons $\mathrm{m}^{-2} \mathrm{~s}^{-1}$. The specific OUR is highest at the optimum OPR and decreases with the decreasing OPR until it reaches a stable value at the end of the experiments.

\section{Discussion}

To be able to gain insight in microalgal respiration during photosynthesis in the light, we measured the oxygen uptake of the algae immediately upon transfer into darkness during different time points in the batch experiments. The post- illumination oxygen uptake rates were thus measured at different biomass concentrations and therefore at different light supply rates. Immediately upon transfer to darkness, photosynthesis stopped, and the $\mathrm{O}_{2}$ present in the dark tube was taken up by the algae within minutes. Both optical microsensors were able to measure this uptake since the response time of both sensors was in the order of seconds. The measured decrease of oxygen is shown in Fig. 5. This measurement was very similar to all other measurements we performed. On each measurement output, we performed linear regression, and we always found a $R^{2}$ of 0.95 or higher and a $P$ value well below 0.05 , indicating that the decrease of $\mathrm{O}_{2}$ was linear. From these measurements, a slope could be calculated, indicating the volumetric OUR in mmol h $\mathrm{hg}^{-1} \mathrm{~kg}^{-1}$. It is also interesting to note that during this measurement, no change in the slope could be detected. On the timescale of these measurements, the oxygen uptake rate did not decrease toward the lower respiration rate of dark adapted algae. This lower dark rate would be reached on a timescale of hours according to the literature (Bate et al. 1988; Geider and Osborne 1989), and with this fast measurement, we were not able to see this lower respiration rate of dark adapted algae. Therefore, the measured OUR must have been predominantly caused by mitochondrial (light) respiration.

Another process that could cause $\mathrm{O}_{2}$ uptake in the light is photorespiration, but we estimated that photorespiration only could take place at a low rate. Ogren (1984) described an equation to calculate the relative rate of photosynthesis versus photorespiration $v_{\mathrm{c}} / v_{\mathrm{o}}$ for isolated Rubisco (Eq. 11). It is important to note that this equation was derived for free Rubisco enzymes and that several transport processes play a role in the functioning of Rubisco in whole cells. Currently, it is not possible to calculate the intracellular $\mathrm{CO}_{2}$ and $\mathrm{O}_{2}$ concentration at the site of Rubisco, and the selectivity of the free enzyme is the only way to estimate whether photorespiration takes place at the concentrations of $\mathrm{O}_{2}$ and $\mathrm{CO}_{2}$ present in the cultivation medium. The specificity factor $S_{\text {rel }}$ was determined experimentally to be 61 for Chlamydomonas reinhardtii (Ogren 1984).

$\frac{v_{\mathrm{c}}}{v_{\mathrm{o}}}=S_{\mathrm{rel}} \frac{\left[\mathrm{CO}_{2}\right]}{\left[\mathrm{O}_{2}\right]}$

At the point of maximum productivity in experiment II, which was higher than for experiment I, the dissolved oxygen reached $122 \%$ air saturation corresponding to an oxygen concentration in the medium of $260 \mu \mathrm{mol} \mathrm{L}^{-1}$. At this point, the concentration dissolved $\mathrm{CO}_{2}$ was $102 \mu \mathrm{mol} \mathrm{L} \mathrm{L}^{-1}$ (corresponding to $1.26 \% v / v \mathrm{CO}_{2}$ in the gas phase, i.e., the logarithmic average of the ingoing and outgoing $\mathrm{CO}_{2}$ volume fractions) as calculated by the method described by Royce and Thornhill (1991). This method is based on the 


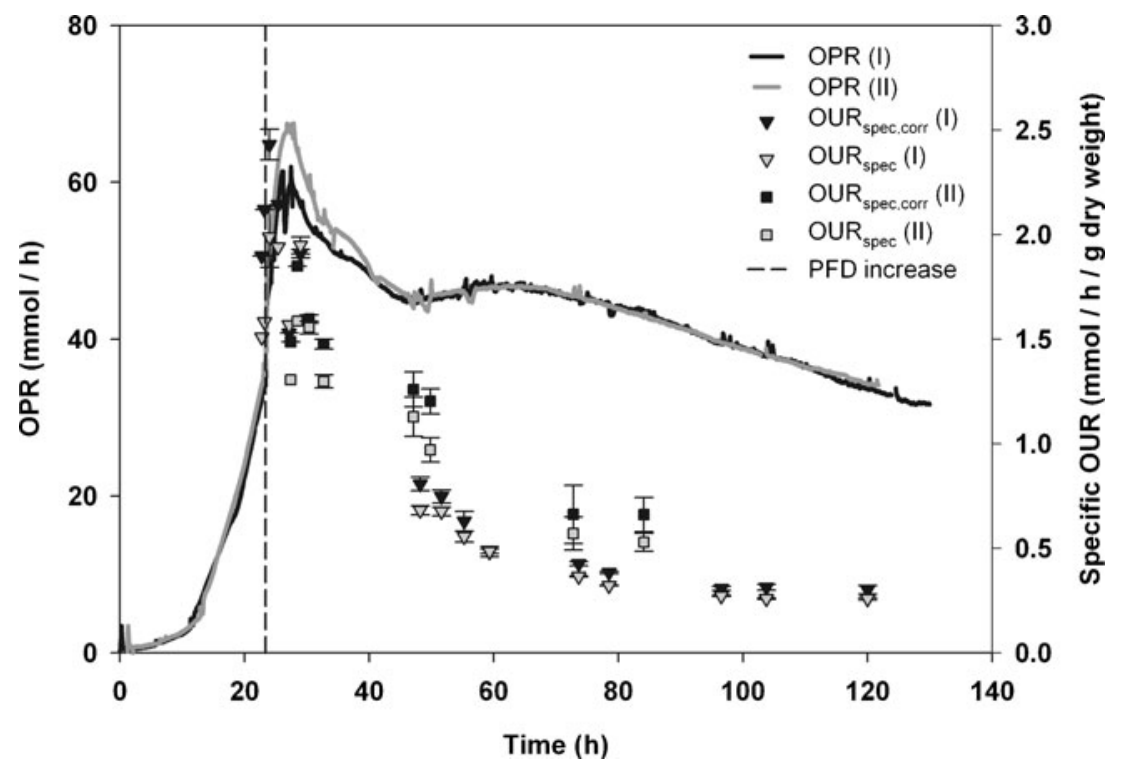

Fig. 7 Specific OUR $\left(\mathrm{mmol} \mathrm{h}^{-1} \mathrm{~g} \mathrm{dw}^{-1}\right)$ for duplicate experiments I and II. The OPR was measured online. The OUR was measured at different time points at which the biomass concentration was also measured. The closed symbols give the corrected values for $\mathrm{OUR}_{\text {spec }}$ $\left(\mathrm{OUR}_{\text {spec,corr }}\right)$, assuming no biofilm build-up in the dark tube and only in the photobioreactor. The open symbols give the values for $\mathrm{OUR}_{\text {spec }}$

measured OPR and dissolved oxygen concentration to calculate the mass transfer coefficient for $\mathrm{O}_{2}$ and subsequently $\mathrm{CO}_{2}$, followed by the calculation of the dissolved carbon dioxide concentration.

The ratio of photosynthesis and photorespiration $v_{\mathrm{c}} / v_{\mathrm{o}}$ then becomes 23.93. This means that the rate of photorespiration is indeed very low, $4 \%$ of photosynthesis, at that point. During the rest of the experiment, the ratio of $\mathrm{CO}_{2}$ to $\mathrm{O}_{2}$ increased again so the rate of photorespiration will have been $<4 \%$ of gross photosynthesis. This is much smaller than the difference between net and gross OPR, and this difference therefore must have been predominantly caused by mitochondrial respiration.

Photorespiration could lead to the accumulation of photorespiratory intermediates, which could still be converted in the photorespiratory pathway upon transfer of the cells to darkness and lead to products that can be respired. This postillumination effect could hypothetically lead to enhanced respiration in the first minutes after transfer to darkness. However, the slope of the respiration measurement (i.e., the rate of decrease of $\mathrm{O}_{2}$ concentration, Fig. 5) did not decrease, indicating that this effect was negligible, which further supports our conclusion that photorespiration as a whole was negligible under the applied cultivation conditions.

To show the total oxygen evolution by photosynthesis (the gross OPR), the online measured net OPR and the OUR were added up. This is shown in Fig. 6. The graphs for both experiments generally show the same pattern, for the assumption that there was a biofilm in the dark tube, and the build-up was equal to that in the whole bioreactor. The error bars represent the standard deviation of duplicate or triplicate OUR measurements at that time point. The light increase to $1,500 \mu \mathrm{mol}$ photons $\mathrm{m}^{-2} \mathrm{~s}^{-1}$ is indicated by a dotted line

although the values for experiment II are slightly higher. This could be due to the use of different microsensors. It is known that the respiration rate is related to the growth rate (Falkowski et al. 1985). Therefore, when the algae are growing faster, more energy for growth is needed, and the OUR will be higher and, consequently, the gross OPR will be higher too as can be seen from our results.

The OUR increases with increasing biomass, and when the PQ (as shown in Fig. 4) stabilizes, the OUR values also become relatively constant. Near the end of both experiments, the OUR starts to increase. When looking at the rates of $\mathrm{O}_{2}$ uptake where the PQ is constant, the gross OPR was $35-40 \%$ higher than the net OPR for both experiments. This is in agreement with the $33 \%$ found by Weger et al. (1989) for Thalassiosira as measured by mass spectrometry, and the $17-43 \%$ found for cyanobacterial biofilms as measured with a Clark-type microsensor (Kühl et al. 1996). Bate et al. (1988) found a difference of $15.6 \%$ for the green alga $D$. tertiolecta.

Compared to specific studies using $C$. sorokiniana, our values are high. In two studies, Vona et al. determined the difference between gross OPR and net OPR to be $5 \%$ for C. sorokiniana (Vona et al. 2004, 1999). However, they used different culture conditions, and more importantly, they used a different, ex situ, method to measure the $\mathrm{O}_{2}$ uptake rate. In the aforementioned study, the respiratory $\mathrm{O}_{2}$ uptake was measured by transferring the cells to a biological oxygen meter (BOM) equipped with an oxygen 
electrode. Transferring the cells from the cultivation vessel to a BOM might result in a lower growth rate and a lower $\mathrm{O}_{2}$ uptake of the cells.

Similar to a previous study (Kliphuis et al. 2010), we observed an optimum OPR and CUR at a biomass concentration of around $2.3 \mathrm{~g} \mathrm{~L}^{-1}$ for both batch experiments with C. sorokiniana (Fig. 4a). This point is the moment where the biomass yield on light energy $\left(Y_{x, E(\mathrm{obs})}\right)$ reaches its maximum value, $0.82 \mathrm{~g} \mathrm{~mol}^{-1}$ for experiment I and $0.87 \mathrm{~g} \mathrm{~mol}^{-1}$ for experiment II. At first, more light was available per cell. Because of this the algae could fix more $\mathrm{CO}_{2}$, produce more $\mathrm{O}_{2}$ and grow faster. While the biomass concentration in the photobioreactor keeps increasing, as can be seen in Fig. 4b, the available light per cell decreases due to mutual shading, and the OPR and CUR reach an optimum. After this point, the OPR and CUR decrease again and keep on doing so until the end of the batch experiment.

This decrease in net OPR and CUR after having reached the optimum can now be related to the specific OUR, which is shown in Fig. 7. The specific OUR is highest at the optimum of the net OPR and decreases together with the net OPR until it reaches a stable value toward the end of the experiments. This trend can be explained by taking into account that part of the respiratory activity is coupled to growth, as discussed before, but that another part is related to the maintenance requirements of the microalgae. Maintenance in this context is defined as energy consumption for purposes other than growth (Pirt 1965). When there is sufficient light available per cell, the algae grow fast and need energy (ATP) to support growth. This energy is supplied by respiration of a part of the carbohydrates produced in photosynthesis, and thus, the specific OUR will be high. A portion of the available light per cell, on the other hand, is needed to generate energy for maintenance, possibly also via respiration of carbohydrates produced in photosynthesis. Thus, after having reached the optimum productivity, the cell density is such that all light is absorbed in the system. When the cell density increases further, the energy extracted from this light (via photosynthesis and respiration) will decrease from a maximal value during the optimum, consisting of a large growth-associated fraction and a smaller but constant maintenance-associated fraction, to a low value, composed of predominantly the constant maintenance-associated fraction.

This analysis is supported by the maintenance requirement of $C$. sorokiniana, which was determined in an independent study of Zijffers et al. (2010). The specific OUR decreases toward the end of the experiments until it reaches a stable value of around $0.3 \mathrm{mmol} \mathrm{O}_{2} \mathrm{~h}^{-1} \mathrm{~g}^{-1}$. This low value for the specific OUR is in the same order as the value for maintenance requirement determined experimentally by Zijffers et al. (2010). Zijffers et al. (2010) determined a maintenance constant of $6.8 \mathrm{mmol}$ photons $\mathrm{g}^{-1} \mathrm{~h}^{-1}$ for $C$. sorokiniana based on the maintenance/ growth model by Pirt (1986). The corresponding yield $Y_{x, E}$

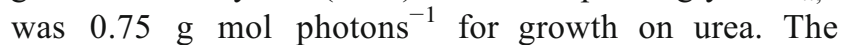
$Y_{x E \max }$ for photoautotrophic growth on urea is estimated to be $1.8 \mathrm{~g} \mathrm{~mol}^{-1}$. The maintenance constant therefore needs to be corrected for this growth inefficiency by multiplying with a factor $0.75 / 1.8$, yielding a corrected maintenance constant of $2.84 \mathrm{mmol}$ photons $\mathrm{g}^{-1} \mathrm{~h}^{-1}$. In the light reaction of photosynthesis, eight photons are used to produce $1 \mathrm{~mol} \mathrm{O}_{2}$. The formed ATP is used to fix $1 \mathrm{~mol} \mathrm{CO}_{2}$ into $1 \mathrm{C}$-mol biomass. When this biomass is respired again, $1 \mathrm{~mol} \mathrm{O}_{2}$ is taken up. When we assume that all $\mathrm{O}_{2}$ uptake is due to maintenance, $1 \mathrm{~mol} \mathrm{O}_{2}$ is taken up per eight photons, giving $2.84 \times 1 / 8=0.36 \mathrm{mmol}$ $\mathrm{O}_{2} \mathrm{~g}^{-1} \mathrm{~h}^{-1}$. This value represents the OUR for maintenance only and corresponds well with the value found in our experiments.

In short, Zijffers et al. determined the maintenance light requirements of $C$. sorokiniana based on the corresponding light use. In this study, we measured the specific oxygen consumption rate, which converged to a low and constant value at the end of the batch cultivation. Recalculating the data from Zijffers et al. to a specific respiratory oxygen consumption shows that both values are almost the same. This shows that respiration could fulfill the maintenance requirements of the microalgal cells.

To conclude, the method described in this paper for measuring the respiration rates of microalgae proved to be a good technique for determining the oxygen uptake in situ during cultivation in a photobioreactor. Only a small and simple extension of the system was necessary to be able to measure respiration rates. This method enables rapid and frequent measurements without disturbing the cultivation and growth of the microalgae. The rate of oxygen uptake in the light gives insight in the gross oxygen evolution by photosynthesis, which is 30 $45 \%$ higher than net oxygen evolution rate. Respiration rates in the light are very high, and consequently, photosynthesis rates are very high to produce sugars, which can be respired to produce extra ATP for growth. Measuring respiration rates during batch cultivation showed the relationship between growth and respiration as an energy supporting mechanism. It also provided strong evidence that respiration could fulfill the maintenance requirement of the microalgal cells.

\section{Nomenclature}

$\eta \quad$ Radius ratio of the photobioreactor (-)

$\mu_{\mathrm{t}} \quad$ Specific growth rate at time $\mathrm{t}\left(\mathrm{h}^{-1}\right)$

$\mathrm{A}_{\mathrm{pbr}} \quad$ Illuminated photobioreactor area $\left(\mathrm{m}^{2}\right)$

CUR Carbon dioxide uptake rate $\left(\mathrm{mmol} \mathrm{h}^{-1}\right)$ 


\begin{tabular}{|c|c|}
\hline CUR $_{\text {cum }}$ & Cumulative carbon dioxide uptake rate (mol) \\
\hline $\mathrm{C}_{\mathrm{x}}$ & $\begin{array}{l}\text { Biomass present in the photobioreactor as } \\
\text { measured with dry weight measurement }(\mathrm{g})\end{array}$ \\
\hline $\mathrm{C}_{\mathrm{x}, \text { tot }}$ & $\begin{array}{l}\text { Total biomass present in the photobioreactor, } \\
\text { including biofilm, calculated from } \mathrm{CO}_{2} \text { uptake } \\
\text { (g) }\end{array}$ \\
\hline $\mathrm{K}_{\mathrm{m}}$ & affinity constant for carbon dioxide $\left(\mu \mathrm{mol} \mathrm{L} \mathrm{L}^{-1}\right)$ \\
\hline $\mathrm{M}_{\text {biomass }}$ & Molar mass of dry biomass $\left(\mathrm{g} \mathrm{mol}^{-1}\right)$ \\
\hline $\mathrm{m}_{\mathrm{E}, \mathrm{x}}$ & Maintenance coefficient $\left(\mathrm{mol} \mathrm{g}^{-1} \mathrm{~h}^{-1}\right)$ \\
\hline $\mathrm{n}_{\text {gas,in }}$ & $\begin{array}{l}\text { Total molar gas flow going into the reactor } \\
\left(\mathrm{mmol} \mathrm{h}^{-1}\right)\end{array}$ \\
\hline $\mathrm{n}_{\text {gas,out }}$ & $\begin{array}{l}\text { Total molar gas flow going out of the reactor } \\
\text { corrected for moisture content }\left(\mathrm{mmol} \mathrm{h}^{-1}\right)\end{array}$ \\
\hline OPR & Oxygen production rate $\left(\mathrm{mmol} \mathrm{h}^{-1}\right)$ \\
\hline OPR $_{\text {gross }}$ & Gross oxygen production rate $\left(\mathrm{mmol} \mathrm{h}^{-1}\right)$ \\
\hline OUR & Oxygen uptake rate $\left(\mathrm{mmol} \mathrm{h}^{-1}\right)$ \\
\hline OUR $_{\text {corr }}$ & $\begin{array}{l}\text { Oxygen uptake rate corrected for biofilm in the } \\
\text { photobioreactor }\left(\mathrm{mmol} \mathrm{h}^{-1}\right)\end{array}$ \\
\hline $\mathrm{OUR}_{\text {spec }}$ & $\begin{array}{l}\text { Oxygen uptake rate per unit biomass } \\
\left(\mathrm{mmol} \mathrm{h}^{-1} \mathrm{~g}^{-1}\right)\end{array}$ \\
\hline PAR & $\begin{array}{l}\text { Photosynthetic active radiation, all photons } \\
\text { between } 400 \text { and } 700 \mathrm{~nm}\end{array}$ \\
\hline $\mathrm{PF}_{\text {in }}$ & $\begin{array}{l}\text { Photon flux on the surface of the } \\
\text { photobioreactor }\left(\mathrm{mmol} \mathrm{h}^{-1}\right)\end{array}$ \\
\hline $\mathrm{PFD}_{\text {in }}$ & $\begin{array}{l}\text { Photon flux density on the surface of the } \\
\text { photobioreactor }\left(\mu \mathrm{mol} \mathrm{m} \mathrm{m}^{-2} \mathrm{~s}^{-1}\right)\end{array}$ \\
\hline PQ & Photosynthetic quotient (-) \\
\hline $\mathrm{r}_{\mathrm{E}, \mathrm{x}}$ & Light supply rate $\left(\mu \mathrm{mol} \mathrm{g} \mathrm{g}^{-1} \mathrm{~s}^{-1}\right)$ \\
\hline $\mathrm{r}_{\mathrm{i}}$ & Radius of inner (rotating) cylinder (m) \\
\hline $\mathrm{r}_{\mathrm{o}}$ & Radius of outer (stationary) cylinder (m) \\
\hline $\mathrm{V}_{\mathrm{pbr}}$ & Photobioreactor volume $(\mathrm{kg})$ \\
\hline $\mathrm{x}_{\mathrm{CO} 2, \mathrm{db}}$ & Molar fraction of $\mathrm{CO}_{2}$ in dry baseline (-) \\
\hline $\mathrm{x}_{\mathrm{CO} 2, \exp }$ & $\begin{array}{l}\text { Molar fraction of } \mathrm{CO}_{2} \text { in experimental gas } \\
\text { data (-) }\end{array}$ \\
\hline $\mathrm{X}_{\mathrm{CO} 2, \mathrm{wb}}$ & Molar fraction of $\mathrm{CO}_{2}$ in wet baseline (-) \\
\hline $\mathrm{X}_{\mathrm{O} 2, \exp }$ & $\begin{array}{l}\text { Molar fraction of } \mathrm{O}_{2} \text { in experimental gas } \\
\text { data (-) }\end{array}$ \\
\hline $\mathrm{x}_{\mathrm{O} 2, \mathrm{wb}}$ & Molar fraction of $\mathrm{O}_{2}$ in dry baseline (-) \\
\hline $\mathrm{Y}_{\mathrm{x}, \mathrm{E}}$ & Biomass yield on light energy $\left(\mathrm{g} \mathrm{mol}^{-1}\right)$ \\
\hline $\mathrm{Y}_{\mathrm{xEmax}}$ & $\begin{array}{l}\text { Maximal yield of biomass on light energy } \\
\left(\mathrm{g} \mathrm{mol}^{-1}\right)\end{array}$ \\
\hline obs) & Observed biomass yield on light energy $\left(\mathrm{g} \mathrm{mol}^{-1}\right)$ \\
\hline
\end{tabular}

Acknowledgements This research project is financially supported by Technology Foundation STW-VICI (WLM.6622). The authors declare that they have no conflict of interest.

Open Access This article is distributed under the terms of the Creative Commons Attribution Noncommercial License which permits any noncommercial use, distribution, and reproduction in any medium, provided the original author(s) and source are credited.

\section{References}

Badger MR, Andrews TJ, Whitney SM, Ludwig M, Yellowlees DC, Leggat W, Price GD (1998) The diversity and coevolution of Rubisco, plastids, pyrenoids, and chloroplast-based $\mathrm{CO}_{2}$-concentrating mechanisms in algae. Can J Bot 76:1052-1071

Bate GC, Sültemeyer JDF, Fock HP (1988) ${ }^{16} \mathrm{O}_{2} /{ }^{18} \mathrm{O}_{2}$ analysis of oxygen exchange in Dunaliella tertiolecta. Evidence for the inhibition of mitochondrial respiration in the light. Photosynth Res 16:219-231

Bauwe H, Hagemann M, Fernie AR (2010) Photorespiration: players, partners and origin. Trends Plant Sci 15:330-336

Eriksen NT, Riisgard FK, Gunther WS, Iversen JJL (2007) On-line estimation of $\mathrm{O}_{2}$ production, $\mathrm{CO}_{2}$ uptake, and growth kinetics of microalgal cultures in a gas-tight photobioreactor. J Appl Phycol 19:161-174

Falkowski PG, Dubinsky Z, Wyman K (1985) Growth-irradiance relationships in phytoplankton. Limnol Oceanogr 30:311-321

Foyer CH, Bloom AJ, Queval G, Noctor G (2009) Photorespiratory metabolism: genes, mutants, energetics, and redox signaling. Annu Rev Plant Biol 60:455-484

Geider RJ, Osborne BA (1989) Respiration and microalgal growth—a review of the quantitative relationship between dark respiration and growth. New Phytol 112:327-341

Graham D (1980) Effects of light on "Dark" respiration. In: Stumpf PK, Conn EE (eds) The biochemistry of plants, vol 2. Academic, NY, pp 525-579

Grande KD, Marra J, Langdon C, Heinemann K, Bender ML (1989) Rates of respiration in the light measured in marine phytoplankton using an ${ }^{18} \mathrm{O}$ isotope-labeling technique. J Exp Mar Biol Ecol 129:95-120

Hoefnagel MHN, Atkin OK, Wiskich JT (1998) Interdependence between chloroplasts and mitochondria in the light and the dark. Biochim Biophys Acta 1366:235-255

Hunt S (2003) Measurements of photosynthesis and respiration in plants. Physiol Plant 117:314-325

Kliphuis AMJ, de Winter L, Vejrazka C, Martens DE, Janssen M, Wijffels RH (2010) Photosynthetic efficiency of Chlorella sorokiniana in a turbulently mixed short light-path photobioreactor. Biotechnol Prog 26:687-696

Kühl M, Glud RN, Ploug H, Ramsing NB (1996) Microenvironmental control of photosynthesis and photosynthesis-coupled respiration in an epilithic cyanobacterial biofilm. J Phycol 32:799-812

López-Gejo J, Haigh D, Orellana G (2009) Relationship between the microscopic and macroscopic world in optical oxygen sensing: a luminescence lifetime microscopy study. Langmuir 26:2144-2150

Mandalam RK, Palsson BO (1998) Elemental balancing of biomass and medium composition enhances growth capacity in high-density Chlorella vulgaris cultures. Biotechnol Bioeng 59:605-611

Maurino VG, Peterhansel C (2010) Photorespiration: current status and approaches for metabolic engineering. Curr Opin Plant Biol $13: 248-255$

Millan-Almaraz JR, Guevara-Gonzalez RG, Romero-Troncoso RD, Osornio-Rios RA, Torres-Pacheco I (2009) Advantages and disadvantages on photosynthesis measurement techniques: a review. Afr J Biotechnol 8:7340-7349

Ogren WL (1984) Photorespiration: pathways, regulation, and modification. Annu Rev Plant Physiol 35:415-442

Peltier G, Thibault P (1985) $\mathrm{O}_{2}$ uptake in the light in Chlamydomonas. Plant Physiol 79:225-230

Pirt SJ (1965) The maintenance energy of bacteria in growing vultures. Proc R Soc Lond B Biol Sci 163:224-231

Pirt SJ (1986) Tansley review no-4 - the thermodynamic efficiency (quantum demand) and dynamics of photosynthetic growth. New Phytol 102:3-37 
Quicker G, Schumpe A, Konig B, Deckwer WD (1981) Comparison of measured and calculated oxygen solubilities in fermentation media. Biotechnol Bioeng 23:635-650

Raghavendra AS, Padmasree K, Saradadevi K (1994) Interdependence of photosynthesis and respiration in plant cells: interactions between chloroplasts and mitochondria. Plant Sci 97:1-14

Royce PNC, Thornhill NF (1991) Estimation of dissolved carbon dioxide concentrations in aerobic fermentations. AlChE J 37:1680-1686

Sorokin C, Myers J (1953) A high-temperature strain of Chlorella. Science 117:330-331

Suresh S, Srivastava VC, Mishra IM (2009) Techniques for oxygen transfer measurement in bioreactors: a review. J Chem Technol Biotechnol 84:1091-1103

Tural BM, Moroney JV (2005) Regulation of the expression of photorespiratory genes in Chlamydomonas reinhardtii. Can J Bot $83: 810-819$

Turpin DH, Elrifi IR, Birch DG, Weger HG, Holmes JJ (1988) Interactions between photosynthesis, respiration, and nitrogen assimilation in microalgae. Can J Bot 66:2083-2097

Tyystjarvi E, Karunen J, Lemmetyinen H (1998) Measurement of photosynthetic oxygen evolution with a new type of oxygen sensor. Photosynth Res 56:223-227
Vona V, Rigano VM, Esposito S, Carillo P, Carfagna S, Rigano C (1999) Growth, photosynthesis, and respiration of Chlorella sorokiniana after $\mathrm{N}$-starvation. Interactions between light, $\mathrm{CO}_{2}$ and $\mathrm{NH}_{4}{ }^{+}$supply. Physiol Plant 105:288-293

Vona V, Di Martino Rigano V, Lobosco O, Carfagna S, Esposito S, Rigano C (2004) Temperature responses of growth, photosynthesis, respiration and NADH: nitrate reductase in cryophilic and mesophilic algae. New Phytol 163:325-331

Weger HG, Herzig R, Falkowski PG, Turpin DH (1989) Respiratory losses in the light in a marine diatom: measurements by short-term mass spectrometry. Limnol Oceanogr 34:11531161

Wingler A, Lea PJ, Quick WP, Leegood RC (2000) Photorespiration: metabolic pathways and their role in stress protection. Philos Trans R Soc B Biol Sci 355:1517-1529

Xue XP, Gauthier DA, Turpin DH, Weger HG (1996) Interactions between photosynthesis and respiration in the green alga Chlamydomonas reinhardtii - characterization of light-enhanced dark respiration. Plant Physiol 112:1005-1014

Zijffers JW, Schippers KJ, Zheng K, Janssen M, Tramper J, Wijffels RH (2010) Maximum photosynthetic yield of green microalgae in photobioreactors. Mar Biotechnol. doi:10.1007/ s1012601092582 